\title{
MỘT SỐ YẾU TỐ NGUY CƠ ĐỐI VỚI TRÀN DỊCH MÀNG PHỔI KÉO DÀI SAU PHẪU THUẬT FONTAN
}

\author{
Trần Đắc Đại*, Lê Ngọc Thành*, Đặng Thị Hải Vân**, Đố Anh Tiến*
}

\section{TÓM TẮT}

Dũ liệu được thu thập từ tất cả các bệnh nhân trẻ em được chẩn đoán tim sinh lý 1 thất và được tiến hành phẫu thuật Fontan tại trung tâm tim mạch- bệnh viện $\mathrm{E}$ từ tháng $8 / 2012$ dến 12/2019. Các bệnh nhân được đặt dẫn lưu màng phổi sau mổ, và tình trạng dẫn lưu có dịch kéo dài liên tục trên 15 ngày sau mổ được xếp vào nhóm biến chứng TDMPKD. Tổng số có 145 bệnh nhân trong nghiên cứu, trong đó 29 bệnh nhân bị TDMPKD (chiếm 20\%). Một số đặc điểm khác biệt giữa 2 nhóm biến chứng và không biến chứng được xác định: tiền sử TDMPKD trước đó $(\mathrm{p}=0,00)$, tiền sử tràn dịch dưỡng chấp trước đó $(\mathrm{p}=0.045)$, tiền sử từng tiến hành can thiệp gây dính màng phổi trước đó $(\mathrm{p}=0.045)$, bất thường giải phẫu vị trí các tạng ngực- bụng $(\mathrm{p}=0,018)$, tình trạng hở van nhĩ thất trước mổ $(\mathrm{p}=0.03)$, tồn tại tuần hoàn bàng hệ lớn trước mổ $(\mathrm{p}=0,041)$, thời gian cặp động mạch chủ trong mổ $(\mathrm{p}=0,04)$ và thời gian chạy tuần hoàn ngoài cơ thể trong mổ $(\mathrm{p}=0,014)$. Phân tích đa biến xác định được một số yếu tố nguy cơ độc lập có liên quan đến gia tăng tỉ lệ biến chứng TDMPKD sau mổ, bao gồm: tình trạng suy tim độ III trở lên trước mổ (OR: 4.93, 95\%CI: $1.19-20.50, \mathrm{p}=0.028$ ), thể bệnh giải phẫu thất phải 2 đường ra (TP2ĐR) có kèm đảo gốc động mạch (ĐGĐM) (OR: 31.00, 95\%CI: 1.35 - 711.63, $\mathrm{p}=0.032)$, tình trạng hở van nhĩ thất trước mổ (OR: 70.73, 95\%CI: 3.28 1523.28, $\mathrm{p}=0.007$ ), tồn tại shunt tâm thất- động mạch phổi từ trước mổ ((OR: 8.29, 95\%CI: 1.6042.78, $\mathrm{p}=0.012)$, chỉ số kích thước động mạch phổi (PAI) trước mổ (OR: 0.98, 95\%CI: 0.97$0.99, \mathrm{p}=0.002)$, và tăng áp lực động mạch phổi trung bình (OR: 1.24, 95\%CI: 1.01-1.53, $\mathrm{p}=0.046$ ). Biến chứng TDMPKD có tỉ lệ xuất hiện tương đối thấp với nhóm bệnh nhân trải qua phẫu thuật Fontan. Việc tìm ra các yếu tố nguy cơ (cả trước, trong và sau mổ) giúp các bác sỹ lâm sàng đưa ra tiên lượng trước phẫu thuật và lên chiến lược dự phòng nhằm làm giảm tỉ lệ xuất hiện biến chứng, cải thiện kết quả đầu ra của phương pháp phẫu thuật Fontan cho các bệnh nhân tim sinh lý 1 thất.

\section{SUMMARY}

To date, despite improvement in survival rate following a Fontan operation, postoperative prolonged pleural effusion (PPE) has still remained a confounding complication of this procedure, which significantly contributing to morbidity and prolonged hospitalization. This study aims to investigate risk factors associated with PPE after the extracardiac Fontan operation. Clinical data was obtained from the medical records of 145 consecutive patients who were diagnosed with single-ventricle lesions and received an extracardiac Fontan operation at the $\mathrm{E}$ Hospital (Hanoi, Vietnam) from August 2012 to December 2019. PPE was defined as the need for a chest tube for $>14$ days. Patients were divided into two groups, those with PPE ( $\mathrm{n}=29,20.00 \%)$ and those without PPE ( $\mathrm{n}=116,80.00 \%)$. During the pre-Fontan evaluation, significant diferences between the two groups were observed in PPE $(p=0.00)$, chylothorax $(p=0.045)$, pleurodesis $(\mathrm{p}=0.045)$, position of thoracic and abdominal organs $(\mathrm{p}=0.018)$, atrioventricular (AV) valve regurgitation $(\mathrm{p}=0.030)$, and large aortapulmonary circulation $(p=0.041)$. During the

\footnotetext{
* Trung tâm Tim mạch Bệnh viện E

** Bệnh viện Nhi Trung Uơng

Người chịu trách nhiệm khoa học: Trần Đắc Đại

Ngày nhận bài: 02/08/2020 - Ngày Cho Phép Đăng: 04/09/2020

Phản Biện Khoa học: PGS.TS. Đặng Ngọc Hùng PGS.TS. Nguyễn Hũu Uớc
} 
Fontan evaluation, significant diferences amongst two groups were seen in aortic cross-clamp time $(\mathrm{p}=0.04)$, cardiopulmonary bypass time $(\mathrm{p}=0.014)$, and mean pulmonary artery pressure (PAP) at Fontan $(\mathrm{p}=0.0072)$. In multivariable analysis with logistic regression, a reduced model including independent predictors for PPE were found to be the III stage of heart failure (OR: 4.93, 95\% CI: 1.19 - 20.50, $\mathrm{p}=0.028$ ), double outlet right ventricle (DORV) with transposition of great arteries (TGA) (OR: 31.00, 95\%CI: 1.35 - 711.63, $\mathrm{p}=0.032$ ), $\mathrm{AV}$ valve regurgitation (OR: 70.73, 95\%CI: $3.28-1523.28, \quad \mathrm{p}=0.007)$, ventricle-to-pulmonary artery shunt (OR: 8.29 , 95\%CI: $1.60-42.78, \mathrm{p}=0.012$ ), PAI (OR: 0.98, 95\%CI: $0.97-0.99, \quad \mathrm{p}=0.002)$ at pre-Fontan, while, at Fontan, high PAP (OR: $1.24,95 \% \mathrm{CI}$ : 1.01-1.53, $\mathrm{p}=0.046)$ was an independent predictor for PPE. In conclusion, the incidence of PPE was relatively low. The III stage of heart failure, primary anatomical diagnosis of DORV with TGA, pre-Fontan AV valve regurgitation, the existence of pre-Fontan ventricle-topulmonary artery shunt, low pulmonary artery index (PAI), and high PAP in the operation were identified as independent risk factors to predict PPE following a Fontan operation. As prior studies also investigated various risk factors for PPE, a preventive strategy that targets these factors combined with previous identified other risk factors might reduce the incidence of PPE.

\section{I. ĐẶT VẤN ĐỀ}

Trong nhiều năm gần đây, cùng với sự tiến bộ của y học nói chung và chuyên ngàng phẫu thuật tim bẩm sinh nói riêng, các bệnh nhân được chẩn đoán tim sinh lý 1 thất được phẫu thuật dựa theo phương pháp tái tạo tuần hoàn Fontan nhiều giai đoạn có tỉ lệ sống sót tăng cao theo thời gian [1], [2]. Tuy nhiên, cùng với việc số lượng bệnh nhân được điều trị ngày càng nhiều và tỉ lệ sống sót ngày càng tăng, sự xuất hiện các biến chứng sau mổ đặc biệt ở giai đoạn sớm trở thành vấn đề với các bác sỹ lâm sàng tại các trung tâm phẫu thuật tim mạch. Tràn dịch màng phổi kéo dài (TDMPKD) là biến chứng đã được biết đến từ lâu, cho đến ngày nay đây vẫn là biến chứng thường gặp nhất, làm gia tăng tỉ lệ bệnh nặng, thời gian nằm viện và gánh nặng $\mathrm{y}$ tế với nhóm bệnh nhân tim sinh lý 1 thất [3]. Nhiều báo cáo tại các cơ sở trung tâm tim mạch trên thế giới nhằm đánh giá và xác định các yếu tố nguy cơ của tình trạng TDMPKD, tuy nhiên đa phần là các báo cáo đơn trung tâm, kết quả không thống nhất về khảo sát và đánh giá các biến số không giống nhau, điều này đòi hỏi sự cần thiết của việc tiếp tục nghiên cứu mở rộng tại các trung tâm khác. Ở Việt Nam, nghiên cứu trước của tác giả Đỗ Anh Tiến đã báo cáo kết quả phẫu thuật Fontan tại Trung tâm tim mạch Bệnh viện $\mathrm{E}$, nhưng các yếu tố nguy cơ đến TDMPKD còn chưa được báo cáo, cũng như các biến số nghiên cứu còn chưa đầy đủ trong quá trình nghiên cứu [4]. Do đó, chúng tôi tiến hành nghiên cứu, với việc khảo sát số lượng lớn các biến số và đặc điểm cả trước, trong và sau mổ nhằm định danh các yếu tố nguy cơ có thể có, liên quan đến tình trạng gia tăng tỉ lệ biến chứng TDMPKS sau phẫu thuật Fontan tại cơ sở.

\section{II. ĐỐI TƯợng VÀ PHƯơng PHÁP NGHIÊN CÚU}

\section{1. Đối tượng nghiên cứu}

Dữ liệu được thu thập từ hồ sơ bệnh án của 145 bệnh nhân liên tiếp được chẩn đoán tim sinh lý 1 thất và được tiến hành phẫu thuật Fontan với ống mạch ngoài tim tại Bệnh viện $\mathrm{E}$ (Hà Nội, Việt Nam) trong 8 năm từ tháng $8 / 2012$ đến hết $12 / 2019$. Tiêu chuẩn lựa chọn bệnh nhân tiến hành phẫu thuật Fontan được mô tả đầy đủ trong bảng 1 . Những trường hợp gia đình bệnh nhân không đồng ý tham gia được loại trừ khỏi nghiên cứu. 
Bảng 1. Tiêu chuẩn lựa chọn bệnh nhân tiến hành phẫu thuật Fontan.

- Tất cả các bệnh nhân được chẩn đoán tim sinh lý 1 thất và đã trải qua phẫu thuật Glenn ở các giai đoạn trước đó.

- Bệnh nhân từ 2 tuổi trở lên, không phân biêt giới tính.

- Áp lực động mạch phổi trung bình $\leq 20 \mathrm{mmHg}$

- Kháng trở hệ mạch máu phổi $\leq 4 \mathrm{Wood}$ unit $/ \mathrm{m}^{2}$

- Chỉ số kích thước động mạch phổi $(\mathrm{PAI}) \geq 150$ và không có bất thường về giải phẫu cây động mạch phổi bao gồm hẹp mức độ từ vừa trở lên các nhánh tại mức rốn phổi.

- Chức năng co bóp tâm thất trong giới hạn bình thường (phân suất tống máu $>50 \%$ )

- Van nhĩ thất không hẹp, không hở hoặc hở mức độ nhẹ- vừa.

- Tĩnh mạch chủ dưới kết nối với tâm nhĩ chung.

- Nhịp cơ bản là nhịp xoang hoặc nhịp nhĩ với trường hợp đồng phân trái.

\subsection{Phương pháp nghiên cứu}

\section{đầu ra}

\subsubsection{Chiến luọ̣c phẫu thuật và kết quả}

Tất cả các bệnh nhân được chẩn đoán tim bẩm sinh dạng sinh lý 1 thất được trải qua phẫu thuật 3 giai đoạn. Ở giai đoạn 1, các phương pháp phẫu thuật được áp dụng bao gồm: phương pháp tạo shunt cấp máu cho phổi; phẫu thuật Banding động mạch phổi; phẫu thuật tạo hình động mạch phổi; phẫu thuật DamusKaye- Stansel (DKS), phẫu thuật Norwood, phẫu thuật tạo hình eo động mạch chủ, phẫu thuật sửa hồi lưu tĩnh mạch phổi, sửa van nhĩthất. Giai đoạn 2, tất cả các bệnh nhân được tiến hành phẫu thuật Glenn 2 hướng (nối tĩnh mạch chủ trên và động mạch phổi). Thông tim đánh giá huyết động được tiến hành thường quy trước khi phẫu thuật Glenn, tuy nhiên do dữ liệu không đầy đủ nên các thông số huyết động ở giai đoạn này không được phân tích trong nghiên cứu. Giai đoạn 3, các bệnh nhân đủ tiêu chuẩn sẽ được tiến hành phẫu thuật Fontan với ống mạch ngoài tim. Trước khi phẫu thuật, các chỉ số liên quan đến tiền sử, thăm khám lâm sàng, khảo sát cấu trúc giải phẫu qua siêu âm Doppler và thăm dò huyết động qua thông tim chụp mạch được ghi nhận. Trong quá trình phẫu thuật Fontan, các thủ thuật được tiến hành kèm theo bao gồm: phẫu thuật tạo cửa sổ, phẫu thuật tạo hình động mạch phổi, mở rộng vách liên nhĩ, thủ thuật DKS, sửa hoặc thay van nhĩ thất, xử lý tuần hoàn bàng hệ chủ phổi bằng phương pháp cắt hoặc thắt. Sau phẫu thuật Fontan, các bệnh nhân được điều trị hồi sức theo phác đồ, ưu tiên việc hạn chế hỗ trợ thông khí nhận tạo càng sớm càng tốt, liệu pháp lợi tiểu và hạn chế dịch, thở oxy bằng gọng mũi và sử dụng thuốc hỗ trợ (vận mạch, kháng sinh, giảm đau...) nếu cần thiết. Tất cả các bệnh nhân được uống aspirin với liều $3-5 \mathrm{mg} / \mathrm{kg} / \mathrm{ngày}$ thay thế heparin duy trì nhằm mục đích chống đông máu. Dẫn lưu màng phổi liên tục sau mổ bằng hệ thống kín. Ghi nhận đặc điểm khám lâm sàng, đo đạc các thông số huyết động sau mổ, đánh giá và phát hiện các biến chứng sớm, tình trạng dẫn lưu (số lượng dịch, màu sắc, xét nghiệm dịch). Ống dẫn lưu màng phổi được rút 
khi lượng dịch đo được dưới ngưỡng 1 $\mathrm{ml} / \mathrm{kg} /$ ngày mà không có tắc nghẽn. Biến chứng TDMPKD được đặt ra trong các trường hợp dẫn lưu màng phổi ra liên tục kéo dài trên 14 ngày sau mổ. Các biến số được khảo sát và phân tích giữa 2 nhóm có biến chứng và không biến chứng nhằm xác định yếu tố nguy cơ làm gia tăng tỉ lệ TDMPKS giai đoạn sớm sau mổ.

\subsubsection{Xử lý số liệu}

Số liệu thô từ phiếu được nhập liệu bằng phần mềm Epidata 3.1, sau đó được xử lý bằng phần mềm Stata ${ }^{\circledR} 15$ (StataCorp LLC, USA). Các biến liên tục được trình bày dưới dạng trung bình, độ lệch chuẩn, và phạm vi dữ liệu. Các biến thứ hạng được trình bày dưới dạng tần số và phần trăm. Phân tích hồi quy đơn biến được sử dụng xác định các yếu tố liên quan đến TDMPKD.
Tổng cộng có 34 biến hợp lệ tại các thời điểm trước Fontan, trong Fontan và sau Fontan được coi là các biến độc lập được đưa vào mô hình đầy đủ với phân tích hồi quy logistic đa biến. Chúng tôi sử dụng chiến lược stepwise backward với giá trị $\mathrm{p}<0,2$; sau đó một mô hình rút gọn với hồi quy logistic đa biến tối giản được thiết lập. Giá trị $\mathrm{p}<0,05$ được coi là có ý nghĩa thống kê.

\subsection{3. Đạo đức nghiên cứu}

Tất cả các quy trình được thực hiện trong nghiên cứu theo Tuyên bố Helsinki năm 1964. Nghiên cứu này đã được phê duyệt bởi Hội Đồng Đạo đức của Đại học $\mathrm{Y}$ Hà Nội. Tất cả những người tham gia trong nghiên cứu đã nhận được sự đồng ý.

\section{KẾT QUẢ NGHIÊN CÚU}

Bảng 2: So sánh các thông số trước mổ giữa 2 nhóm có và không mắc biến chứng TDMPKD

\begin{tabular}{|c|c|c|c|c|}
\hline \multirow{3}{*}{ Biến số trước mổ } & \multirow{2}{*}{$\begin{array}{l}\text { Tổng số } \\
(n=145)\end{array}$} & \multicolumn{2}{|c|}{ TDMPKD } & \multirow{3}{*}{$\begin{array}{c}\mathbf{p} \\
\text { value }\end{array}$} \\
\hline & & Có $(n=29)$ & Không $(n=116)$ & \\
\hline & $\begin{array}{c}\text { Tần số } \\
\text { (\% của tống) }\end{array}$ & $\begin{array}{c}\text { Tần số } \\
\text { (\% của tống) }\end{array}$ & $\begin{array}{c}\text { Tần số } \\
\text { (\% của tống) }\end{array}$ & \\
\hline Giới nữ & $60(41.38)$ & $11(37.93)$ & $49(42.24)$ & 0.673 \\
\hline Liệt cơ hoành & $1(0.69)$ & $0(0.00)$ & $1(0.86)$ & 0.616 \\
\hline Tiền sử TDMPKD & $3(2.07)$ & $3(10.34)$ & $0(0.00)$ & 0.000 \\
\hline Tràn dịch dưỡng chấp & $1(0.69)$ & $1(3.45)$ & $\mathbf{0}(\mathbf{0 . 0 0 )}$ & 0.045 \\
\hline Gây dính màng phổi & $1(0.69)$ & $1(3.45)$ & $0(0.00)$ & 0.045 \\
\hline Biến chứng thần kinh & $3(2.07)$ & $0(0.00)$ & $3(2.59)$ & 0.382 \\
\hline Suy tim & & & & 0.056 \\
\hline Độ II & $73(50.34)$ & $10(34.48)$ & $63(54.31)$ & \\
\hline Độ III & $72(45.69)$ & $19(65.52)$ & $53(45.69)$ & \\
\hline Điện tâm đồ & & & & 0.706 \\
\hline Nhịp xoang & $134(92.41)$ & $26(89.66)$ & $108(93.10)$ & \\
\hline Nhịp nhĩ & $5(3.45)$ & $1(3.45)$ & $4(3.45)$ & \\
\hline Nhịp bộ nối & $6(4.14)$ & $2(6.90)$ & $4(3.45)$ & \\
\hline \multicolumn{5}{|l|}{ Thể bệnh tim 1 thất } \\
\hline Teo van ba lá & $24(16.55)$ & $3(10.34)$ & $21(18.10)$ & 0.315 \\
\hline
\end{tabular}




\begin{tabular}{|c|c|c|c|c|}
\hline Teo/ thiểu sản van hai lá & $10(6.9)$ & $4(13.79)$ & $6(5.17)$ & 0.101 \\
\hline Một thất 2 đường vào & $21(14.48)$ & $2(6.9)$ & $19(16.38)$ & 0.194 \\
\hline Bệnh Ebstein & $4(2.76)$ & $0(0.00)$ & $4(3.45)$ & 0.311 \\
\hline Teo phổi- vách liên thất nguyên vẹn & $3(2.07)$ & $0(0.00)$ & $3(2.59)$ & 0.382 \\
\hline Đảo gốc động mạch có sửa chữa & $10(6.9)$ & $1(3.45)$ & $9(7.76)$ & 0.413 \\
\hline $\begin{array}{l}\text { Thấp phải } 2 \text { đường ra- đảo gốc } \\
\text { động mạch }\end{array}$ & $43(29.66)$ & $11(37.93)$ & $32(27.59)$ & 0.275 \\
\hline Thông sàn nhĩ thất thể không cân xứng & $22(15.17)$ & $6(20.69)$ & $16(13.79)$ & 0.354 \\
\hline Thông sàn nhĩ thất kèm đảo gốc & $8(5.52)$ & $2(6.9)$ & $6(5.17)$ & 0.716 \\
\hline Situs tạng ngực- bụng & & & & 0.018 \\
\hline Situs solitus & $108(74.48)$ & $17(58.62)$ & $91(78.45)$ & \\
\hline Situs inversus & $22(15.17)$ & $5(17.24)$ & $17(14.66)$ & \\
\hline Situs ambiguus & $15(10.34)$ & $7(24.14)$ & $8(6.9)$ & \\
\hline Kiểu hình tâm thất hệ thống & & & & 0.202 \\
\hline Thất phải & $35(24.14)$ & $10(34.48)$ & $25(21.55)$ & \\
\hline Thất trái & $35(24.14)$ & $3(10.34)$ & $32(27.59)$ & \\
\hline 2 tâm thất & $58(40.00)$ & $12(41.38)$ & $46(39.66)$ & \\
\hline Không xác định & $17(11.72)$ & $4(13.79)$ & $13(11.21)$ & \\
\hline Số van nhĩ thất & & & & 0.618 \\
\hline Một & $69(47.59)$ & $15(51.72)$ & $54(46.55)$ & \\
\hline Hai & $76(52.41)$ & $14(48.28)$ & $62(53.45)$ & \\
\hline Mức độ hở van nhĩ thất & & & & $\mathbf{0 . 0 3 0}$ \\
\hline Không & $37(25.52)$ & $3(\mathbf{1 0 . 3 4 )}$ & $34(29.31)$ & \\
\hline Nhẹ & $79(54.48)$ & $22(75.86)$ & $57(49.14)$ & \\
\hline Vừa & $29(20.00)$ & $4(13.79)$ & $25(21.55)$ & \\
\hline Tình trạng van nhĩ thất & & & & 0.746 \\
\hline Van bình thường & $141(97.24)$ & $28(96.55)$ & $113(97.41)$ & \\
\hline Van cơ học & $1(0.69)$ & $0(0.00)$ & $1(0.86)$ & \\
\hline Van sinh học & $3(2.07)$ & $1(3.45)$ & $2(1.72)$ & \\
\hline Cản trở đường ra tâm thất hệ thống & $8(5.52)$ & $1(3.45)$ & $7(6.03)$ & 0.585 \\
\hline Hẹp dưới van chủ & $5(3.45)$ & $1(3.45)$ & $4(3.45)$ & 1.00 \\
\hline Lỗ TLT hạn chế & $3(2.07)$ & $0(0.00)$ & $3(2.59)$ & 0.382 \\
\hline $\begin{array}{l}\text { Hẹp miệng nối tĩnh mạch chủ- động } \\
\text { mạch phổi }\end{array}$ & $1(0.69)$ & $0(0.00)$ & $1(0.86)$ & 0.616 \\
\hline Bất thường giải phẫu động mạch phổi & $1(0.69)$ & $0(0.00)$ & $1(0.86)$ & 0.616 \\
\hline Còn ống động mạch & $2(1.38)$ & $1(3.45)$ & $1(0.86)$ & 0.285 \\
\hline Tuần hoàn bàng hệ chủ- phổi & $15(10.34)$ & $0(0.00)$ & $15(12.93)$ & 0.041 \\
\hline $\begin{array}{l}\text { Shunt tồn lưu thất phải- động mạch } \\
\text { phổi }\end{array}$ & $50(34.48)$ & $13(44.83)$ & $37(31.90)$ & 0.190 \\
\hline $\begin{array}{l}\text { Tuần hoàn bàng hệ chủ- phổi lớn } \\
\text { trên thông tim }\end{array}$ & $50(34.48)$ & $7(24.14)$ & $43(37.07)$ & 0.190 \\
\hline
\end{tabular}




\begin{tabular}{lllll}
\hline & Mean (SD) & Mean (SD) & Mean (SD) & \\
\hline Tuổi khi phẫu thuật Fontan (tháng) & $68.07(54.01)$ & $58.38(28.55)$ & $70.50(58.52)$ & 0.8510 \\
\hline Chiều cao khi phẫu thuật Fontan $(\mathrm{cm})$ & $102.57(20.02)$ & $100.76(13.23)$ & $103.03(21.41)$ & 0.9232 \\
\hline Cân nặng khi phẫu thuật Fontan $(\mathrm{kg})$ & $16.45(8.13)$ & $15.05(4.11)$ & $16.81(8.83)$ & 0.9152 \\
\hline PAP $(\mathrm{mmHg})(\mathrm{n}=142)$ & $11.42(2.16)$ & $11.52(2.61)$ & $11.39(2.14)$ & 0.705 \\
\hline VEDP $(\mathrm{mmHg})(\mathrm{n}=129)$ & $5.05(1.62)$ & $5.26(1.48)$ & $4.99(1.66)$ & 0.4208 \\
\hline PAI $\left(\mathrm{mm}^{2} / \mathrm{m}^{2}\right)(\mathrm{n}=137)$ & $319.46(124.27)$ & $277.72(86.94)$ & $329.70(130.11)$ & 0.0759 \\
\hline Rp $\left(\right.$ wood $\left./ \mathrm{m}^{2}\right)(\mathrm{n}=64)$ & $1.91(0.80)$ & $2.16(0.98)$ & $1.85(0.74)$ & 0.1633 \\
\hline
\end{tabular}

*NYHA Heart Failure Classification; PAP: áp lực động mạch phổi; VEDP: áp lực cuối tâm trương tâm thất hệ thống; PAI: chỉ số kích thước động mạch phổi; Rp: sức cản hệ mạch phổi

Các chỉ số nghiên cứu thời điểm trước phẫu thuật của nhóm bệnh nhân được mô tả ở bảng 2 . Tổng số 145 bệnh nhân trải qua phẫu thuật Fontan trong thời gian nghiên cứu, trong đó có 60 trẻ gái $(41,38 \%)$, độ tuổi trung bình tại thời điểm phẫu thuật là 68,07 tháng, chiều cao trung bình là $102,57 \mathrm{~cm}$ và cân nặng trung bình là $16,45 \mathrm{~kg}$. Về đặc điểm lâm sàng trước mổ, số bệnh nhân có tình trạng suy tim NYHA II và III tương đương nhau. Ngoài ra, 134 bệnh nhân có nhịp tim cơ bản là nhịp xoang trên điện tâm đồ, chỉ có 6 bệnh nhân nhịp bộ nối $(4,14 \%)$ và 5 bệnh nhân nhịp nhĩ $(3,45 \%)$. Thể bệnh giải phẫu của dạng tim sinh lý 1 thất thường gặp nhất trong nghiên cứu là TP2ĐR có ĐGĐM ( $n=43,29,66 \%)$, các dạng tiếp theo lần lượt là teo van ba lá $(\mathrm{n}=24,16,55 \%)$, thông sàn nhĩ thất $(\mathrm{n}=22,15.17 \%)$, tim 1 thất 2 đường vào $(n=21,14.48 \%)$, teo/thiểu sản van hai lá $(n=10,6.9 \%)$ ĐGĐM có sửa chữa $(n=10$, 6.9\%). Bên cạnh đó, 108 bệnh nhân có kiểu hình situs solitus $(74,48 \%), 22$ bệnh nhân kiểu hình situs inversus $(15,17 \%)$. Đặc điểm giải phẫu tâm thất hệ thống là thất trái và thất phải gặp với tỉ lệ tương đương nhau (35 bệnh nhân mỗi trường hợp, 24\%), ngoài ra có 58 bệnh nhân có kiểu hình cả 2 thất $(40 \%)$ và 17 trường hợp tâm thất không xác định kiểu hình $(11,72 \%)$. Về đặc điểm van nhĩ thất, 69 bệnh nhân có 1 van $(47,59 \%)$ và 76 bệnh nhân có đủ 2 van $(52,41 \%)$. Hơn một nửa số bệnh nhân có tình trạng hở van mức độ nhẹ $(54,48 \%)$ và 29 bệnh nhân hở van mức độ vừa $(20 \%)$. Có 8 trường hợp có tắc nghẽn đường ra tuần hoàn hệ thống, trong đó 5 trường hợp hẹp dưới van chủ và 3 ca còn lại do lỗ thông liên thất hạn chế. Bên cạnh đó, siêu âm Doppler phát hiện 1 trường hợp hẹp miệng nối Glenn, 1 trường hợp có hẹp giải phẫu động mạch phổi. Các trường hợp tồn tại shunt bất thường cấp máu cho phổi sau phẫu thuật Glenn gồm 2 trường hợp còn shunt qua ống động mạch $(1,38 \%), 15$ trường hợp tồn tại tuần hoàn bàng hệ chủ- phổi lớn $(10,34 \%)$ và 50 bệnh nhân còn tồn tại shunt tâm thất- động mạch phổi $(34,48 \%)$.

Các thông số huyết động đánh giá qua thông tim chụp mạch trước phẫu thuật Fontan cũng được mô tả trong bảng 2 . Áp lực động mạch phổi trung bình là $11.42 \pm 2.16 \mathrm{mmHg}$ (đo ở 142 bệnh nhân), áp lực cuối tâm trương thất hệ thống trung bình là $5.05 \pm 1.62 \mathrm{mmHg}$ (đo ở 129 bệnh nhân). Chỉ số kích thước ĐMP trung bình là $319.46 \pm 124.27 \mathrm{~mm}^{2} / \mathrm{m}^{2}$ (đo ở 137 bệnh nhân). Kháng trở hệ thống mạch máu phổi trung bình là $1.91 \pm 0.80$ đơn vị Wood $/ \mathrm{m}^{2}$ (đo ở 64 bệnh nhân). Đồng thời qua thông tim cũng phát hiện 50 trường hợp còn tồn tại tuần hoàn bàng hệ chủphổi $(34.48 \%)$. Một số yếu tố khác biệt giữa 2 nhóm không bị biến chứng TDMPKD và nhóm có biến chứng tìm thấy trong nghiên cứu: tiền sử TDMPKD trước đó $(\mathrm{p}=0.00)$, tiền sử từng bì tràn dịch dưỡng chấp trước đó $(p=0.045)$, gây dày dính màng phổi trước đó $(\mathrm{p}=0.045)$, kiểu hình situs tạng và tâm nhĩ $(\mathrm{p}=0.018)$ và tồn tại tuần hoàn bàng hệ chủ- phổi $(p=0.041)$ (bảng 2$)$. 
Bảng 3: So sánh các thông số trong và sau mổ giữa 2 nhóm có và không bị biến chứng TDMPKD

\begin{tabular}{|c|c|c|c|c|}
\hline \multirow{3}{*}{ Biến số nghiên cứu } & \multirow{2}{*}{$\begin{array}{l}\text { Tổng số } \\
(\mathrm{n}=145)\end{array}$} & \multicolumn{2}{|c|}{ TDMPKD } & \multirow{3}{*}{ p value } \\
\hline & & Có $(n=29)$ & $\begin{array}{c}\text { Không } \\
(n=116)\end{array}$ & \\
\hline & $\begin{array}{c}\text { Tần số } \\
\text { (\% của tống) }\end{array}$ & $\begin{array}{c}\text { Tần số } \\
\text { (\% của tống) }\end{array}$ & $\begin{array}{c}\text { Tần số } \\
\text { (\% của tống) }\end{array}$ & \\
\hline \multicolumn{5}{|l|}{ Trong mổ } \\
\hline Tạo cửa sổ Fontan & $145(100.00)$ & $29(100.00)$ & $116(100.00)$ & - \\
\hline Tạo hình động mạch phổi & $15(10.34)$ & $3(10.34)$ & $12(10.34)$ & 1.00 \\
\hline Thủ thuật DKS & $4(2.76)$ & $1(3.45)$ & $3(2.59)$ & 0.800 \\
\hline Sửa van nhĩ thất & $4(2.76)$ & $0(0.00)$ & $4(3.45)$ & 0.311 \\
\hline Thay van nhĩ thất & $1(0.69)$ & $0(0.00)$ & $1(0.86)$ & 0.616 \\
\hline Mở rộng vách liên nhĩ & $16(11.03)$ & $1(3.45)$ & $15(12.93)$ & 0.145 \\
\hline Cắt tuần hoàn bàng hệ & $1(0.69)$ & $0(0.00)$ & $1(0.86)$ & 0.616 \\
\hline Thắt tuần hoàn bàng hệ & $1(0.69)$ & $0(0.00)$ & $1(0.86)$ & 0.616 \\
\hline $\begin{array}{l}\text { Kẹp động mạch chủ (có liệt } \\
\text { tim) }\end{array}$ & $126(86.90)$ & $26(89.66)$ & $100(86.21)$ & 0.623 \\
\hline Chảy máu & $7(4.83)$ & $2(6.9)$ & $5(4.31)$ & 0.561 \\
\hline \multicolumn{5}{|l|}{ Sau mổ } \\
\hline \multirow[t]{2}{*}{ Phù } & $9(6.21)$ & $3(10.34)$ & $6(5.17)$ & 0.302 \\
\hline & Mean (SD) & Mean (SD) & Mean (SD) & \\
\hline \multicolumn{5}{|l|}{ At Fontan } \\
\hline $\begin{array}{l}\text { Thời gian kẹp động mạch } \\
\text { chủ (phút) }(\mathrm{n}=126)\end{array}$ & $48.87(24.04)$ & $56.65(20.55)$ & $46.84(24.56)$ & 0.040 \\
\hline $\begin{array}{l}\text { Thời gian chạy tuần hoàn } \\
\text { ngoài cơ thể (phút) }\end{array}$ & $82.90(29.39)$ & $91.90(25.35)$ & $80.66(29.99)$ & 0.014 \\
\hline $\begin{array}{l}\text { Thời gian chạy máy hỗ trợ } \\
\text { (phút) }\end{array}$ & $19.38(13.55)$ & $20.69(13.25)$ & $19.04(13.67)$ & 0.3665 \\
\hline PAP (mmHg) & $15.12(3.49)$ & $16.93(4.17)$ & $14.67(3.16)$ & 0.0072 \\
\hline \multicolumn{5}{|l|}{ Sau mổ } \\
\hline PAP (mmHg) & $16.24(9.35)$ & $16.03(3.36)$ & $16.29(10.33)$ & 0.2787 \\
\hline
\end{tabular}

DKS: Damus-Kaye-Stansel, PAP: áp lực động mạch phổi

Bảng 3 mô tả những đặc điểm trong và sau quá trình phẫu thuật Fontan giữa 2 nhóm có và không có biến chứng TDMPKD sau mổ. Các thủ thuật được tiến hành đồng thời với phẫu thuật Fontan bao gồm: phẫu thuật tạo cửa sổ $(n=145,100 \%)$, phẫu thuật tạo hình động mạch phồi $(n=15,10.34 \%)$, mở rộng vách liên nhĩ $(n=16,11.03 \%)$, thủ thuật $\mathrm{DKS}(\mathrm{n}=4,2.76 \%)$, sửa van nhĩ thất $(\mathrm{n}=4,2.76 \%)$, thay van nhĩ thất $(n=1,0.69 \%)$, xử lý tuần hoàn bàng hệ chủ phổi bằng phương pháp cắt $(n=1,0.69 \%)$ hoặc thắt $(n=1,0.69 \%)$. Có 126 bệnh nhân được tiến hành phẫu thuật có cặp động mạch chủ $(86,9 \%)$, còn lại phẫu thuật với tim đập. Các biến chứng ngay trong và sau mổ gồm 7 trường hợp chảy máu $(4,83 \%)$ và 9 trường hợp phù phổi (6,21\%). Các đặc điểm khác biệt có ý nghĩa giữa 2 nhóm được xác định bao gồm thời gian cặp động mạch chủ $(\mathrm{p}=0.04)$, thời gian chạy tuần hoàn ngoài cơ thể $(\mathrm{p}=0.014)$, và áp lực động mạch phổi trung bình ngay sau mổ $(\mathrm{p}=0.0072)$. 
Bảng 4: Mối liên quan giữa nhóm biến số trước mổ và biến chứng TDMPKD sau mổ: phân tích đơn biến

\begin{tabular}{|c|c|c|c|}
\hline \multirow{2}{*}{ Biến số nghiên cứu } & \multicolumn{3}{|c|}{ Phân tích đơn biến } \\
\hline & OR & $95 \% \mathrm{CI}$ & p value \\
\hline Giới (so với nam) & 1 & - & \\
\hline Nữ & 0.84 & $0.36-1.93$ & 0.674 \\
\hline Tuổi & 0.99 & $0.98-1.00$ & 0.284 \\
\hline Chiều cao & 0.99 & $0.97-1.02$ & 0.585 \\
\hline Cân nặng & 0.97 & $0.91-1.03$ & 0.307 \\
\hline Độ suy tim (so với độ II) & 1 & - & \\
\hline Độ III & 2.26 & $0.97-5.28$ & 0.06 \\
\hline Điện tim (so với nhịp xoang) & 1 & - & \\
\hline Nhịp nhĩ & 1.04 & $0.11-9.68$ & 0.974 \\
\hline Nhịp bộ nối & 2.08 & $0.36-11.96$ & 0.413 \\
\hline \multicolumn{4}{|l|}{ THể bệnh tim 1 thất } \\
\hline Teo van ba lá (so với nhóm còn lại) & 1 & - & \\
\hline Có & 0.52 & $0.14-1.89$ & 0.321 \\
\hline Teo/ thiểu sản van hai lá (so với nhóm còn lại) & 1 & - & \\
\hline Có & 2.93 & $0.77-11.18$ & 0.115 \\
\hline Một thất 2 đường vào (so với nhóm còn lại) & 1 & - & \\
\hline Có & 0.38 & $0.08-1.73$ & 0.209 \\
\hline Đảo gốc động mạch có sửa chữa (so với nhóm còn lại) & 1 & - & \\
\hline Có & 0.42 & $0.05-3.49$ & 0.426 \\
\hline TP2ĐR có ĐGĐM (so với nhóm còn lại) & 1 & - & \\
\hline Có & 1.60 & $0.68-3.77$ & 0.278 \\
\hline TSNT thể không cân xứng (so với nhóm còn lại) & 1 & - & \\
\hline Có & 1.63 & $0.58-4.62$ & 0.358 \\
\hline TSNT kèm ĐGĐM (so với nhóm còn lại) & 1 & - & \\
\hline Có & 1.36 & $0.26-7.10$ & 0.717 \\
\hline Vị trí tạng ngực-bụng (so với situs solitus) & 1 & - & \\
\hline Situs inversus & 1.57 & $0.51-4.84$ & 0.429 \\
\hline Situs ambiguus & 4.68 & $1.50-14.63$ & 0.008 \\
\hline Kiểu hình tâm thất hệ thống (so với thất phải) & 1 & - & \\
\hline Thất trái & 0.23 & $0.06-0.94$ & 0.041 \\
\hline 2 tâm thất & 0.65 & $0.25-1.72$ & 0.388 \\
\hline Không xác định kiểu hình & 0.77 & $0.21-2.94$ & 0.701 \\
\hline Số van nhĩ thất (so với 1 van) & 1 & - & \\
\hline Hai van & 0.81 & $0.36-1.84$ & 0.618 \\
\hline Hở van nhĩ thất (so với không hở) & 1 & - & \\
\hline Có & 3.59 & $1.02-12.67$ & $\mathbf{0 . 0 4 7}$ \\
\hline \multicolumn{4}{|l|}{ Tình trạng van nhĩ thất (so với van bình thường) } \\
\hline Van sinh học & - & - & \\
\hline Van cơ học & 2.02 & $0.18-23.06$ & 0.672 \\
\hline
\end{tabular}




\begin{tabular}{|c|c|c|c|}
\hline Cản trở tuần hoàn hệ thống (so với nhóm còn lại) & 1 & - & \\
\hline Có & 0.56 & $0.07-4.71$ & 0.590 \\
\hline Hẹp dưới van chủ (so với nhóm còn lại) & 1 & - & \\
\hline Có & 1.00 & $0.11-9.30$ & 1.00 \\
\hline Còn ống động mạch (so với nhóm còn lại) & 1 & - & \\
\hline Có & 4.11 & $0.25-67.70$ & 0.323 \\
\hline $\begin{array}{l}\text { Shunt tồn lưu tâm thất- động mạch phổi (so với nhóm } \\
\text { còn lại) }\end{array}$ & 1 & - & \\
\hline Có & 1.73 & $0.76-3.98$ & 0.193 \\
\hline \multicolumn{4}{|l|}{ Thông tim } \\
\hline \multicolumn{4}{|l|}{ Tuần hoàn bàng hệ chủ- phổi lớn (so với không có) } \\
\hline Có & 0.54 & $0.21-1.37$ & 0.194 \\
\hline PAP $(\mathrm{mmHg})(\mathrm{n}=142)$ & 1.03 & $0.85-1.24$ & 0.776 \\
\hline $\operatorname{VEDP}(\mathrm{mmHg})(\mathrm{n}=129)$ & 1.10 & $0.86-1.42$ & 0.443 \\
\hline PAI $(n=137)$ & 0.99 & 0.9908 - 0.9999 & 0.049 \\
\hline $\mathrm{Rp}\left(\operatorname{wood} / \mathrm{m}^{2}\right)(\mathrm{n}=64)$ & 1.68 & $0.75-3.77$ & 0.210 \\
\hline
\end{tabular}

*NYHA Heart Failure Classification; TP2ĐR: thất phải 2 đường ra; ĐGĐM: đảo gốc động mạch; TSNT: thông sàn nhĩ thất, PAP: áp lực động mạch phổi; VEDP: áp lực cuối tâm trương thất; PAI: chỉ số kích thước động mạch phổi; Rp: sức cản hệ mạch phổi; OR: tỉ suất chênh; $95 \% \mathrm{CI}$ : khoảng tin cậy $95 \%$.

Dựa vào phương pháp phân tích đơn biến, các yếu tố nguy cơ được phân tích và mô tả trong bảng 4 , cụ thể xác định 4 yếu tố bao gồm: kiểu hình situs ambigous (OR: 4.68, 95\%CI: 1.50 - 14.63, $\mathrm{p}=0.008)$, tâm thất hệ thống kiểu hình thất trái $(\mathrm{OR}: 0.23,95 \% \mathrm{CI}: 0.06-0.94, \mathrm{p}=0.041)$, hở van nhĩ thất hệ thống (OR: 3.59, 95\%CI: 1.02 - 12.67, p=0.047), và chỉ số kích thước ĐMP thấp (OR: 0.99, $95 \%$ CI: $0.9908-0.9999, \mathrm{p}=0.049$ )

Bảng 5: Mối tương quan giữa các thông số trong và sau mổ với biến chứng TDMPKD: phân tích đơn biến

\begin{tabular}{|c|c|c|c|}
\hline \multirow{2}{*}{ Biến số nghiên cứu } & \multicolumn{3}{|c|}{ Phân tích đa biến } \\
\hline & OR & $95 \% \mathrm{CI}$ & p value \\
\hline \multicolumn{4}{|l|}{ Trong mổ } \\
\hline Tạo hình động mạch phổi (so với nhóm còn lại) & 1 & - & \\
\hline Có & 1 & $0.26-3.80$ & 1.00 \\
\hline Thủ thuật DKS (so với nhóm còn lại) & 1 & - & \\
\hline Có & 1.35 & $0.13-13.43$ & 0.801 \\
\hline Mở rộng vách liên nhĩ (so với nhóm còn lại) & 1 & - & \\
\hline Có & 0.24 & $0.03-1.90$ & 0.177 \\
\hline Có kẹp động mạch chủ (so với nhóm còn lại) & 1 & - & \\
\hline Có & 1.39 & $0.38-5.12$ & 0.624 \\
\hline Chảy máu (so với nhóm còn lại) & 1 & - & \\
\hline Có & 1.64 & $0.30-8.94$ & 0.565 \\
\hline Thời gian cặp động mạch chủ (phút) (n=126) & 1.02 & $0.99-1.03$ & 0.074 \\
\hline
\end{tabular}




\begin{tabular}{llll}
\hline Thời gian chạy tuần hoàn ngoài cơ thể (phút) & 1.01 & $0.99-1.02$ & 0.080 \\
\hline Thời gian chạy máy hỗ trợ (phút) & 1.01 & $0.98-1.04$ & 0.580 \\
\hline PAP (mmHg) & $\mathbf{1 . 2 1}$ & $\mathbf{1 . 0 7 - 1 . 3 7}$ & $\mathbf{0 . 0 0 3}$ \\
\hline Sau mổ & & & \\
\hline PAP (mmHg) & 1.00 & $0.95-1.05$ & 0.897 \\
\hline $\begin{array}{l}\text { Phù (so với nhóm còn lại) } \\
\text { Có }\end{array}$ & 1 & - & \\
\hline
\end{tabular}

DKS: Damus-Kaye-Stansel; PAP: áp lực động mạch phổi; OR: tỉ suất chênh; $95 \% \mathrm{CI}$ : khoảng tin cậy $95 \%$.

Phân tích đơn biến với các yếu tố trong và sau mổ được mô tả trong bảng 5. Giá trị áp lực động mạch phổi trung bình cao ngay sau mổ được xác định là yếu tố nguy cơ liên quan đến biến chứng TDMPKD

Table 6. Mối liên quan giữa các thông số trước, trong và sau mổ với biến chứng TDMPKD sau mổ Fontan: phân tích đa biến

\begin{tabular}{|c|c|c|c|}
\hline \multirow[t]{2}{*}{ Biến số nghiên cứu } & \multicolumn{3}{|c|}{ Phân tích đa biến } \\
\hline & OR & $95 \% \mathrm{CI}$ & p value \\
\hline Suy tim * (so với độ II) & 1 & - & \\
\hline Độ III & 4.93 & $1.19-20.50$ & 0.028 \\
\hline ĐGĐM có sửa chữa (so với nhóm còn lại) & 1 & - & \\
\hline Có & 24.83 & $0.52-1187.93$ & 0.104 \\
\hline TP2ĐR có ĐGĐM (so với nhóm còn lại) & 1 & - & \\
\hline Có & 31.00 & $1.35-711.63$ & 0.032 \\
\hline TSNT thể không cân xứng (so với nhóm còn lại) & 1 & - & \\
\hline Có & 0.24 & $0.03-1.80$ & 0.164 \\
\hline Số van nhĩ thất (so với 1 van) & 1 & - & \\
\hline Hai van & 0.14 & $0.01-2.62$ & 0.189 \\
\hline Vị trí các tạng ngực- bụng (so với situs solitus) & 1 & - & \\
\hline Situs inversus & - & - & \\
\hline Situs ambiguus & 5.80 & $0.90-37.22$ & 0.064 \\
\hline Kiểu hình tâm thất hệ thống (so với thất phải) & 1 & - & \\
\hline Thát trái & - & - & \\
\hline Hai thất & - & - & \\
\hline Không xác định & 12.01 & $0.70-206.24$ & 0.087 \\
\hline Hở van nhĩ thất (so với nhóm còn lại) & 1 & - & \\
\hline Có & 70.73 & $3.28-1523.28$ & 0.007 \\
\hline Shunt tồn lưu tâm thất- động mạch phổi (so với nhóm còn lại) & 1 & - & \\
\hline Có & 8.29 & $1.60-42.78$ & 0.012 \\
\hline PAI & 0.98 & $0.97-0.99$ & 0.002 \\
\hline PAP ngay trong mổ & 1.24 & $1.01-1.53$ & 0.046 \\
\hline PAP sau mổ & 0.87 & $0.72-1.06$ & 0.176 \\
\hline
\end{tabular}


*NYHA Heart Failure Classification; TP2ĐR: thất phải 2 đường ra; ĐGĐM: đảo gốc động mạch; TSNT: thông sàn nhĩ thất, PAP: áp lực động mạch phổi;; PAI: chỉ số kích thước động mạch phổi; OR: tỉ suất chênh; $95 \%$ CI: khoảng tin cậy $95 \%$.

Tổng số 34 yếu tố độc lập cả trước, trong và sau mổ được tiến hành phân tích đa biến. Qua đó rút ra kết luận về 7 yếu tố nguy cơ độc lập có liên quan đến tỉ lệ xuất hiện biến chứng TDMPKD sau phẫu thuật Fontan bao gồm: tình trạng suy tim mức độ NYHA III trước mổ (OR: 4.93, 95\% CI: 1.19 20.50, $\mathrm{p}=0.028)$, thể giải phẫu bệnh tim TP2ĐR có ĐGĐM (OR: 31.00, 95\%CI: 1.35 - 711.63, $\mathrm{p}=0.032$ ), hở van nhĩ thất (OR: 70.73,95\%CI: 3.28 - 1523.28, $\mathrm{p}=0.007)$, tồn tại shunt tâm thất- động mạch phổi (OR: $8.29,95 \% \mathrm{CI}$ : 1.60-42.78, $\mathrm{p}=0012)$, chỉ số kích thước động mạch phổi thấp (OR: 0.98 , $95 \% \mathrm{CI}: 0.97-0.99, \mathrm{p}=0.002)$ và giá trị áp lực động mạch phổi ngay sau mổ cao $(\mathrm{OR}: 1.24,95 \% \mathrm{CI}$ : $1.01-1.53, \mathrm{p}=0.046)$.

\section{BÀN LUẬN}

Biến chứng TDMPKD sau phẫu thuật Fontan là hệ quả từ sự tác động của nhiều cơ chế, trong đó vai trò chủ đạo là do sự thay đổi đột ngột về giải phẫu dẫn đến mất hoàn toàn chức năng dẫn hồi lưu máu từ ngoại vi về tim do áp lực âm từ thời kỳ tâm trương, hiện tượng "mất nhịp đập" của dòng chảy tĩnh mạch dẫn máu về phổi, dẫn tới hiện tượng ứ trệ và thoát dịch do tái phân bố (giống như "suy tim phải"); ngoài ra còn có sự tham gia của phản ứng viêm và hiện tượng phù nề, hiện tượng giảm albumin máu sau mổ, sự thay đổi vai trò hoạt động của hormone... Trong nghiên cứu của chúng tôi tî̉ lệ gặp biến chứng TDMPKD sau mổ Fontan là 29/145 bệnh nhân (chiếm tỉ lệ $20 \%$ ). Với cùng định nghĩa về tiêu chuẩn bệnh, tác giả Gupta báo cáo tỉ lệ biến chứng TDMPKD sau phẫu thuật Fontan là 37\% [6]; con số này theo báo cáo của tác giả $\mathrm{Fu}$ là $38,9 \%$ [7] và tác giả Kim là 42,4\% [8]. Nghiên cứu của chúng tôi cũng tìm ra một số yếu tố độc lập được xác định là nguy cơ cao liên quan với biến chứng TDMPKD sau mổ, gồm: tình trạng suy tim độ III trước mổ, thể bệnh TP2ĐR có ĐGĐM, hở van nhĩ thất trước mổ, tồn tại shunt tâm thất hệ thống- động mạch phổi trước mổ, chỉ số kích thước ĐMP thấp và áp lực ĐMP trung bình cao ngay sau mổ. Do sự không thống nhất và thiếu liên tục giữa các nghiên cứu khác nhau về tiêu chuẩn lựa chọn bệnh nhân, tiêu chuẩn lựa chọn các chỉ số nghiên cứu, và một phần phụ thuộc chủ quan vào đánh giá và kinh nghiệm tại từng trung tâm trên thế giới, kết quả đưa ra từ các báo cáo có sự khác nhau khá rõ ràng và trải rộng ở nhiều nhóm đặc điểm khác nhau. Theo Gupta, chỉ có 2 yếu tố nguy cơ làm gia tăng tỉ lệ TDMPKD sau mổ gồm: chỉ số bão hòa oxy thấp trước mổ, và biến chứng nhiễm trùng sau mổ [6]. Tác giả $\mathrm{Fu}$ đưa ra kết luận việc không tiến hành thủ thuật mở cửa sổ trong mổ, nồng độ bão hòa oxy thấp trước mổ và nhiễm trùng sau mổ là các yếu tố liên quan chặt chẽ với tỉ lệ biến chứng TDMPKD. Gần đây nhất, báo cáo của Kim và các cộng sự nghiên cứu hồi cứu trong 13 năm từ 2005 đến 2018 đưa ra kết luận thể giải phẫu hội chứng thiểu sản tim trái, áp lực tĩnh mạch trung ương cao tại thời điểm phẫu thuật Glenn và việc sử dụng thủ thuật tạo cửa sổ là yếu tố tiên lượng độc lập cho tình trạng TDMPKD sau mổ. Mặc dù trong nghiên cứu của mình, chúng tôi đã thu thập và phân tích 1 số lượng lớn các chỉ số độc lập, tuy nhiên nhiều chỉ số không đạt đủ điều kiện thích hợp để tiến hành phân tích đa biến. Sự khác biệt này phần nào phản ánh sự khác biệt về khả năng chuyên môn về ngoại khoa tại từng trung tâm tim mạch, sự đa dạng về các thể giải phẫu bệnh tim được phẫu thuật cũng như kinh nghiệm quản lý và điều trị các bệnh nhân tim bẩm sinh dạng 1 tâm thất ở từng cơ sở.

Về phân loại hoạt động cơ năng đánh giá mức độ suy tim theo NYHA, tất cả 145 bệnh nhân trong nghiên cứu thuộc phân loại NYHA II 
hoặc III. Nghiên cứu của chúng tôi tìm ra tình trạng suy tim là yếu tố tiên lượng độc lập với TDMPKD sau mổ, cụ thể các bệnh nhân thuộc phân loại suy tim NYHA III có tỉ lệ gặp biến chứng tràn dịch kéo dài hơn nhóm bệnh nhân phân loại NYHA II. Về cơ chế và đặc điểm bệnh học, thay đổi chức năng tim gắn với tình trạng "quá tải" về thể tích (tiền gánh) hoặc áp lực (hậu gánh). Điều này có thể là hệ quả từ quá trình điều trị các giai đoạn 1 và 2 không đúng thời điểm hoặc không đạt được mụa tiêu mong muốn. Do đó, tình trạng suy tim từ trước mổ có thể tiếp tục diễn tiến cả ngay sau mổ, và với các biểu hiện của suy tim sớm thì tràn dịch màng phổi là 1 dấu hiệu rất thường gặp. Đặc biệt với chẩn đoán tim sinh lý 1 thất, chức năng tim phụ thuộc rất nhiều vào mức độ hẹp hoặc hở van nhĩ thất, lưu lượng tuần hoàn phổi (liên quan đến quá tải thể tích), mức độ tắc nghẽn tuần hoàn hệ thống (liên quan đến quá tải áp lực), cũng như việc bệnh nhân thường phải trải qua nhiều cuộc phẫu thuật trước đó- tất cả đều có tác động nhất định đến chức năng tim [9]. Điều này cũng tương đồng với kết quả nghiên cứu của chúng tôi về tình trạng hở van nhĩ thất là yếu tố nguy cơ liên quan đến TDMPKD.

Chỉ số kích thước động mạch phổi thấp, tương đương với việc hạn chế về lưu lượng dòng chảy hồi lưu từ tĩnh mạch hệ thống, dẫn tới hệ quả là hiện tượng ứ trệ máu tĩnh mạch, gây thoát dịch ra khoảng kẽ và các khoang tự nhiên. Đây cũng là cơ chế tham gia gây TDMPKD. Điều này được chứng minh phần nào trong nghiên cứu bởi sự gia tăng áp lực động mạch phổi tại thời điểm ngay sau phẫu thuật có liên quan đến TDMPKD theo phương pháp phân tích đa biến rút gọn. Ngoài ra, áp lực ĐMP trung bình cao theo nhiều báo cáo là yếu tố nguy cơ của thất bại với tuần hoàn Fontan giai đoạn sớm [10], [11]. Điều này cũng cho thấy giá trị áp lực ĐMP cao là con số phản ánh sự thay đổi huyết động theo hướng xấu đối với tuần hoàn Fontan, và có cơ chế tương đồng với TDMPKD.
Về phân loại giải phẫu các thể bệnh tim bẩm sinh dạng 1 tâm thất, nghiên cứu của chúng tôi xác định thể bệnh TP2ĐR có ĐGĐM chiếm tỉ lệ cao nhất trong nhóm bệnh nhân TDMPKD $(\mathrm{n}=43,29,66 \%)$. Điều đáng chú ý rằng đây là thể giải phẫu tim có đầy đủ cấu trúc 2 tâm thất, chức năng thất thường được bảo tồn tốt, với 2 vòng van và van nhĩ thất tương đối bình thường.

Qua siêu âm Doppler và thông tim chụp mạch, phát hiện có 50 bệnh nhân tồn tại shunt tâm thất- động mạch phổi trước phẫu thuật Fontan. (34,48\%), đồng thời nghiên cứu cũng chỉ ra sự tồn tại của shunt tâm thất- động mạch phổi là yếu tố nguy cơ của tình trạng TDMPKD. Về cơ chế bệnh sinh, shunt tồn lưu tâm thất- động mạch phổi là nguyên nhân gây quá tải tuần hoàn phổi (do nó cung cấp 1 dòng chảy "có nhịp đập" đưa máu lên phổi bên cạnh dòng chảy tự nhiên từ tĩnh mạch chủ trên qua miệng nối Glenn), từ đó dẫn tới tăng áp lực ĐMP, và nếu kéo dài sẽ làm thay đổi cả kháng trở hệ mạch máu phổi. Chúng tôi hiểu rằng sự tồn tại dòng chảy bất thường này có liên quan đến kỹ thuật xử lý trong quá trình phẫu thuật giai đoạn II tại cơ sở thực hành (về nguyên tắc ở giai đoạn II bên cạnh việc tạo miệng nối giữa tĩnh mạch chủ trên và động mạch phổi, cần loại bỏ hoàn toàn các nguồn cấp máu khác cho phổi như ống động mạch hoặc dòng chảy từ tâm thất lên động mạch phổi). Kết quả nghiên cứu này cũng góp phần đưa ra khuyến cáo cho phẫu thuật viên thay đổi chiến lược và kỹ thuật xử lý ở các giai đoạn trước Fontan nhằm hạn chế biến chứng giai đoạn muộn.

Thủ thuật mở cửa sổ với ống mạch ngoài tim tiến hành trong phẫu thuật Fontan có thể ảnh hưởng đến tình trạng TDMPKD, điều này đã được xem xét trong một vài nghiên cứu trước đây; tuy nhiên, cũng có những kết quả nghiên cứu cho thấy lợi ích của cửa sổ Fontan trong việc hạn chế các biến chứng sớm sau mổ [12]. Sự tồn tại của cửa sổ thông giữa ống mạch nhân tạo và tâm nhĩ chung nhằm duy trì 1 dòng chảy dạng shunt 
phải- trái ở tầng nhĩ, góp phần cải thiện cung lượng tim ở pha cấp ngay sau mổ [13], [14], [15]. Báo cáo của tác giả Kim dựa vào phân tích đa biến trên 85 bệnh nhân được tiến hành phẫu thuật mở cửa sổ cho thấy giảm đáng kể tỉ lệ TDMPKD, trong khi đó nghiên cứu hồi cứu ngẫu nhiên của Lemler và các cộng sự cũng chỉ ra phẫu thuật Fontan có mở cửa sổ làm giảm đáng kể cả thời gian đặt dẫn lưu cũng như lượng dịch dẫn lưu hàng ngày của bệnh nhân sau mổ [16]. Chưa dừng lại, nhiều báo cáo về lợi ích của phương pháp phẫu thuật mở cửa sổ với tuần hoàn Fontan giúp cải thiện kết quả đầu ra nói chung mà không chỉ với 1 biến chứng cụ thể như TDMPKD [1], [15], với các lợi ích được chứng minh bao gồm: cải thiện thể tích đổ đầy, tăng cung lượng tim, cải thiện khả năng vận chuyển và cung cấp oxy, giảm áp lực tĩnh mạch hệ thống qua đó làm giảm tình trạng phù và thoát dịch. Điểm đáng ghi nhận tại trung tâm chúng tôi tiến hành phẫu thuật mở cửa sổ ở tất cả các bệnh nhân trải qua phẫu thuật Fontan- và cũng do đó, thủ thuật mở cửa sổ không được đánh giá và phân tích như 1 yếu tố nguy cơ với các nhóm biến chứng sau mổ.

Nghiên cứu của chúng tôi hiện tại vẫn còn một số điểm hạn chế. Thứ nhất, đây là nghiên cứu hồi cứu đơn trung tâm. Tất cả các bệnh nhân nhận được liệu trình điều trị dựa trên kinh nghiệm và chuyên môn của một nhóm nhỏ các phẫu thuật viên, do đó thiếu tính đại diện cho các trung tâm khác.Thứ hai, mặc dù rất nhiều các biến số được khảo sát và phân tích, một số chỉ số có tính trùng lặp hoặc không đồng nhất có thể vẫn tồn tại. Thứ ba, cỡ mẫu trong nghiên cứu còn tương đối hạn chế, dẫn đến hệ quy chiếu của nghiên cứu có thể không đầy đủ tính khách quan và phản ánh chính xác một số biến số, cũng như các yếu tố chủ quan, phức tạp và không đồng nhất do tiến trình phẫu thuật, hoặc các dữ liệu thu thập qua thông tim chụp mạch không đầy đủ.

\section{KẾT LUẬN}

Mặc dù tỉ lệ biến chứng TDMPKD sau phẫu thuật Fontan trong nghiên cứu là tương đối thấp so với nhiều báo cáo khác trên thế giới, đây vẫn là một vấn đề nan giải với các bác sỹ lâm sàng. Nghiên cứu đưa ra kết luận các yếu tố độc lập có liên quan đến gia tăng tỉ lệ biến chứng TDMPKD sau mố bao gồm suy tim mức độ NYHA III, thể giải phẫu TP2ĐR có ĐGĐM, hở van nhĩ thất hệ thống, tồn tại shunt tâm thất- động mạch phổi trước mố, chỉ số kích thước ĐMP thấp và áp lực động mạch phổi cao ngay sau mổ. Dựa trên kết quả này, chiến lược điều trị dự phòng có thể được đưa ra nhằm mục tiêu thay đổi các yếu tố tiên lượng, qua đó làm giảm tỉ lệ biến chứng và cải thiện kết quả đầu ra.

\section{TÀI LIỆU THAM KHẢO}

1. Gaynor, J.W., et al., Predictors of outcome after the Fontan operation: is hypoplastic left heart syndrome still a risk factor? The Journal of Thoracic and Cardiovascular Surgery, 2002. 123(2): p. 237-245.

2. Lee, J.R., et al., Surgical results of patients with a functional single ventricle. European journal of cardio-thoracic surgery, 2003. 24(5): p. 716-722.

3. Murphy, M.O., et al., Management of early Fontan failure: a single-institution experience. European Journal of Cardio-Thoracic Surgery, 2014. 46(3): p. 458-464.

4. Đỗ Anh Tiến, Nghiên cưu ưng dụng phẫu thuật Fontan với ống nối ngoài tim điều trị tim bẩm sinh dạng một tâm thất tại Trung tâm tim mạch - Bệnh viện E. 2017, Đại học Y Hà Nội.

5. Pike, N.A., et al., Reduced pleural drainage, length of stay, and readmissions using a modified Fontan management protocol. The Journal of thoracic and cardiovascular surgery, 2015. 150(3): p. 481-487.

6. Corda, R., Reducing Fontan effusions: A day saved is a dollar earned. The Journal of 
thoracic and cardiovascular surgery, 2015. 150(3): p. 488.

7. Gupta, A., et al., Risk factors for persistent pleural effusions after the extracardiac Fontan procedure. The Journal of thoracic and cardiovascular surgery, 2004. 127(6): p. 1664-1669.

8. Fu, S., Z.-c. Feng, and S. Dietmar, Factors influencing pleural effusion after Fontan operation: an analysis with 95 patients. Chinese Medical Sciences Journal, 2010. 25(1): p. 38-43.

9. Kim, G., et al., Risk Factors for Prolonged Pleural Effusion After Extracardiac Fontan Operation. Pediatric cardiology, 2019. 40(8): p. 1545-1552.

10. Allen, H.D., et al., Moss \& Adams' heart disease in infants, children, and adolescents: including the fetus and young adult. 2013: Lippincott Williams \& Wilkins.

11. Kaulitz, R., et al., Modified Fontan operation in functionally univentricular hearts: preoperative risk factors and intermediate results. The Journal of thoracic and cardiovascular surgery, 1996. 112(3): p. 658-664.
12. Cazzaniga, M., et al., Operación modificada de Fontan o variantes efectuadas en un solo tiempo quirúrgico. Determinantes de la mortalidad. Revista Española de Cardiología, 2002. 55(4): p. 391-412.

13. Tweddell, J.S., et al., Fontan palliation in the modern era: factors impacting mortality and morbidity. The Annals of thoracic surgery, 2009. 88(4): p. 1291-1299.

14. Fu, S., et al., Fontan extracardiac tunnel connection: fenestration or not? Chinese medical journal, 2009. 122(19): p. 2335-2338.

15. Jacobs, M.L. and W.I. Norwood Jr, Fontan operation: influence of modifications on morbidity and mortality. The Annals of thoracic surgery, 1994. 58(4): p. 945-952.

16. Bridges, N.D., et al., Effect of baffle fenestration on outcome of the modified Fontan operation. Circulation, 1992. 86(6): p. 1762-1769.

17. Lemler, M.S., et al., Fenestration improves clinical outcome of the Fontan procedure: a prospective, randomized study. Circulation, 2002. 105(2): p. 207-212. 